\title{
Study on Social Psychological Factors of Property and Violent Criminals -- Based on the Investigation and Analysis of Criminals in City A
}

\author{
Guan Wang \\ College of Behavioral and Social Sciences, University of Maryland, Collge Park, 20742, United \\ States. \\ 2859101181@qq.com
}

\begin{abstract}
Objective: to explore the social psychological factors of violent crime and property crime, so as to provide a basis for effective crime prevention. Methods: 51 criminals qualified for violent crimes and 52 criminals qualified for property crimes were selected in the jail of city A. Meanwhile, according to the matching principle of age, gender and violent crime group, 50 cases of non-criminal persons without criminal experience were selected as the control group. Childhood trauma questionnaire (CTQ), social support revalued scale (SSRS), Eysenck personality questionnaire (EPQ) and family assessment device (FAD) were used for the measurement. Results: the scores of emotional abuses, sexual abuse, physical neglect of CTQ, psychoticism and neuroticism of EPQ, FAD communication and the overall function in the violent crime group were all higher than those in the property crime group and the control group [for example, emotional abuse score: $(8.9 \pm 0.4)$ vs. (6. $7 \pm 0.3),(6.2 \pm 0.5)$, all $P<0.05$. The score of objective support of SSRS was lower than that of the property crime group and the control group $(P<0.05)$. The overall scores of emotional neglect of CTQ, neuroticism, introversion and extroversion of EPQ, FAD problem solving in the property crime group were all higher than those in the control group (all $P<0.05$ ). Logistic regression analysis showed that emotional abuse of CTQ, psychoticism, neuroticism, introversion and extroversion of $E P Q$, and overall family function of $F A D$ are the risk factors for violent crime $(O R=1.43,1.06,1.42$, 8.57, 140.60). Emotional neglect of CTQ, neuroticism, introversion and extroversion of EPQ, FAD problem solving function are the risk factors for property crime $(O R=1.48,1.05,1.12,11.16)$. Conclusion: violent crime and property crime may be related to childhood trauma experience, personality traits and family dysfunction.
\end{abstract}

Keywords: Violent crime, Property crime, Risk factors, Inventory survey.

\section{Introduction}

Crime is a complex social phenomenon related to many factors and is the result of the interaction of various negative factors in society [1]. Crime is not caused by any single factor, but the result of the joint action of individuals, families, interpersonal and social factors [2]. There are many schools of theory about the causes of crime. The comprehensive motivation theory of crime divides the factors influencing the formation of criminal psychology into "dominant factors" and "external factors" [3]. "Dominant factors" refer to the physiological condition, psychology and behaviour development level which the formation of criminal psychology depends on. Psychological factors refer to the bad factors existing in the original psychological structure of the subject which are closely related to the formation of criminal psychology, including the bad factors in personality tendency and gender structure. Through these bad psychological factors, criminals actively absorb the bad factors outside the main body, thus internalizing the criminal psychology. "External factors" refers to the objective factors outside the subject that are related to the formation of criminal psychology, including social environmental factors, natural environmental factors and situational factors. Social environmental factors include political, economic, cultural, spiritual, legal and other major social environmental factors, as well as family, school, work, residence, communication, occupation and other minor environmental factors. Natural environmental factors include region, season, time, natural disaster and other factors. Situational factors include the victim, the scene and others, conditions and atmosphere. According to the theory of problem behaviour [4], the development of adolescents' problem behaviour is affected by the social psychological system. The social psychological system 
consists of three parts: individual system, perceived social environmental system and behaviour system. Individual system emphasizes ideas, emotions, and problem-solving ability. Perceived social environmental system includes four sub-systems which are family, peer, school, and neighbourhood. The behaviour system (hereafter referred to as bad behaviours) includes smoking, drinking, substance abuse, unhealthy behaviours, anti-social behaviours, illegal behaviours and other problematic behaviours, as well as general behaviours such as poor academic performance [4]. These are all risk factors for individual crime. Without early intervention, individuals with problem behaviours may deviate towards the crime track.

In real life, violent crime and property crime have been the main types of crime in recent years, although there are many kinds of ways of crime. Violent crime refers to crimes, such as murder, intentional injury, rape and robbery that directly infringe or endanger citizens' personal rights and democratic rights under the threat of violence or violence. Property crime refers to non-violent means, mainly property infringement crimes, such as fraud, corruption, theft, illegal production, etc. [1].

According to the above theories, this study hypothesizes that criminal behaviour is related to childhood trauma experience (which can be classified as social environmental factors, social environmental system), social support system (which can be classified as social environmental factors, social environmental system), personality traits (which can be classified as dominant factors, individual system) and family dysfunction (which can be classified as social environmental factors and social environmental system). And violent crime and property crime exist differences in the above factors. This study intends to explore the social psychological factors of violent crime and property crime by collecting the data of the juvenile growth environment, family function assessment, social support system and personality factors of the criminals in custody, so as to provide a basis for the effective prevention of crime.

\section{Objects and Methods}

\subsection{Objects}

Crime group: the illegal criminals detained in the detention centre of city A from February 2016 to February 2018 were selected. The case has been solved and the facts of the case are cleared. The criminals are also approved to be arrested by the procuratorate or sentenced by the first instance of the court. During the survey period, there were 947 to 1043 actual detainees in detention centres, and the ratio of male to female was about 7:3. Ten percent of the total sample size and a ratio of 7:3 of male to female were selected to match the age, sex and marital status of violent and property criminals. Results were that a total of 116 people were selected and 13 people refused to participate in the survey (9 in the violence group and 4 in the property group), with 103 valid samples. Among them, 51 members of the violent crime group were aged from 16 to 60 with 36 men and 15 women. Marital status: 31 single, 16 married, 4 divorced or widowed. Average education year: $(10.0 \pm 3.3)$ years. 52 members of the property crime group were aged from 16 to 60 with 36 men and 16 women. Marital status: 31 single, 16 married, 5 divorced or widowed. Average education year: $(10.0 \pm 3.5)$ years. Each subject in the crime group had to read or have their informed consent read by a counsellor before participating in the study. The researchers promised the people in crime group that all personal data involved would be kept confidential. Criminals have the right to opt out, and participation or nonparticipation will not have any impact on the case. On the premise of informed consent of all the subjects, the questionnaire was completed under the guidance of professional psychological consultants in a separate psychological consultation room.

Control group: according to the matching principle of age, gender, marital status and crime group, the college students, staff members and office workers of city A who volunteered to participate in this study were selected on the premise of informed consent. There were 50 non-criminals with no criminal experience and their ages ranged from 16 to 60 with 35 men and 15 women. Marital status: 30 single, 16 married, 4 divorced or widowed; Average education year: (13.8 \pm 3.1$)$ years. 
There was no statistical significance in the differences of age, sex and marital status between the three groups (all P 0.05). The years of education in the control group were higher than those in the violent crime group and property crime group $(\mathrm{F}=22.26, \mathrm{P}<0.001)$.

\subsection{Tools}

\subsubsection{Childhood Trauma Questionnaire (CTQ) [5]}

There are a total of 28 items, including 5 factors: emotional abuse, physical abuse, sexual abuse, emotional neglect and physical neglect. Grade 1(never) $\sim 5$ (always) 5 is used, and some items are reverse-rated. The higher the score, the more abuse and neglect an individual suffers.

\subsubsection{Social Support Revalued Scale (SSRS) [6]}

There are 10 items in total, including objective support (3 items), subjective support (4 items) and utilization of social support ( 3 items). The higher the score, the more support you get.

\subsubsection{Psychological Assessment Software}

The following two questionnaires were completed on the computer using the complete version of psychological test system 4.0 developed by Shanghai beechen software company.

Eysenck personality questionnaire (EPQ) adult version: there are a total of 88 items, including four dimensions: psychoticism, introversion and extroversion, neuroticism and disguise.

Family Assessment Device (FAD): there are a total of 60 items, which are divided into 7 subscales: problem solving, communication, role, emotional response, emotional intervention, behaviour control and overall function. Each item 1 (very agree or very similar to my family) $\sim 3$ (totally disagree or completely unlike my family) grade 4; some items are reverse-rated, with a score of 5 minus the actual score. The higher the score, the greater the loss of family function.

\subsection{Statistical Methods}

Use SPSS 13.0 software. Demographic data adopted one way analysis of variance and and $\chi 2$ test. Covariance analysis was used to compare groups. For the data with statistical significance, the LDS pairwise comparison was further used. Non-conditional logistic stepwise regression analysis was used to explore the related factors of violent crime and property crime. $\mathrm{P}<0.05$ was considered to be statistically significant.

\section{Results}

\subsection{Comparison of Scale Scores Between the Three Groups}

The scores of emotional abuse, physical neglect, sexual abuse, psychoticism, introversion and extroversion, neuroticism, communication function and overall function of the violent crime group were higher than those of the property crime group and the control group, and the score of objective support was lower than that of property crime group and control group. The scores of the property crime group were higher than that of the control group (table 1) in terms of emotional neglect, introversion and extroversion, neuroticism, problem solving and overall function (table 1)

\subsection{Logistic Regression Analysis of Crime-Related Factors}

\subsubsection{Logistic Regression Analysis of Factors Related to Violent Crime}

The violent crime group was taken as the case group and the non-criminal group as the control group. Taking whether there was violent crime as the dependent variable, all factors of CTQ, SSRS, EPQ and FAD were divided into independent variables. Taking education years as the coverable, non-conditional logistic stepwise regression analysis was carried out. The advance method was used to eliminate variables according to Wald test results. Results are that the factors entering into the equation were CTQ emotional abuse factor, EPQ, psychoticism, neuroticism, introversion and extroversion factor, and overall family function factor of FAD (table 2). 


\subsubsection{Logistic Regression Analysis of Factors Related to Property Crime}

Property criminals were taken as the case group and non-criminal persons as the control group. Taking whether there was property crime as the dependent variable, all factors of CTQ, SSRS, EPQ and FAD were divided into independent variables. Taking education years as the coverable, nonconditional logistic stepwise regression analysis was carried out. The advance method was used to eliminate variables according to Wald test results. Results are that the factors entering into the equation were CTQ emotion neglect factor, EPQ neuroticism, introversion and extroversion factor, FAD problem solving factor (table 3).

Table 1. Comparison of scale scores between three groups $(\mathrm{x} \pm \mathrm{s})$; Violent crime group Property crime group Control group Pairwise comparison

\begin{tabular}{|c|c|c|c|c|c|}
\hline Scale & $(\mathrm{n}=51)$ & $(\mathrm{n}=52)$ & $(\mathrm{n}=50)$ & $F$ & $P<0.05$ \\
\hline \multicolumn{6}{|l|}{ Childhood trauma questionnaire } \\
\hline Emotional abuse & $8.9 \pm 0.4$ & $6.7 \pm 0.3$ & $6.5 \pm 0.5$ & 9. $31^{* * *}$ & (1) $>$ (2) $>$ (3) \\
\hline Physical abuse & $6.5 \pm 0.5$ & $6.3 \pm 0.4$ & $6.3 \pm 0.5$ & 0.05 & \\
\hline Sexual abuse & $7.6 \pm 0.3$ & $5.7 \pm 0.2$ & $5.4 \pm 0.2$ & 3. $40^{* *}$ & (1) $>$ (2) (3) \\
\hline Emotional neglect & $9.7 \pm 0.8$ & $10.8 \pm 0.6$ & $9.6 \pm 0.7$ & 7. $24^{*}$ & (2) $>$ (1) (3) \\
\hline Physical neglect & $10.0 \pm 0.5$ & $8.6 \pm 0.5$ & $8.4 \pm 0.4$ & 3. $45^{*}$ & (1) $>$ (2) (3) \\
\hline \multicolumn{6}{|l|}{ Social Support revalued scale } \\
\hline Objective support & $7.2 \pm 0.5$ & $9.0 \pm 0.4$ & $8.6 \pm 0.5$ & $5.73^{*}$ & (2) (3) $>$ (1) \\
\hline Subjective support & $22.7 \pm 0.7$ & $22.4 \pm 0.7$ & $20.9 \pm 0.8$ & 2.76 & \\
\hline Utilization of support & $7.7 \pm 0.3$ & $7.5 \pm 0.30$ & $7.7 \pm 0.4$ & 0.20 & \\
\hline $\begin{array}{l}\text { Total score } \\
\text { Eysenck personality questionnaire }\end{array}$ & $38.7 \pm 1.2$ & $39.9 \pm 1.8$ & $37.0 \pm 1.3$ & 1.39 & \\
\hline Psychoticism & $52.3 \pm 1.3$ & $49.9 \pm 1.2$ & $44.3 \pm 1.4$ & $3.92^{*}$ & (1) $>$ (2) (3) \\
\hline Introversion and extroversion & $53.6 \pm 1.4$ & $57.8 \pm 1.3$ & $49.9 \pm 1.5$ & 8. $93 * * *$ & (2) $>$ (1) $>$ (3) \\
\hline Neuroticism & $57.7 \pm 1.7$ & $55.2 \pm 1.5$ & $52.4 \pm 1.8$ & $6.73^{*}$ & (1) (2) $>$ (3) \\
\hline Disguise & $52.2 \pm 1.4$ & $51.7 \pm 1.3$ & $51.9 \pm 1.5$ & 0.05 & \\
\hline \multicolumn{6}{|l|}{ Family Assessment Device } \\
\hline Problem solving & $2.1 \pm 0.1$ & $2.3 \pm 0.1$ & $2.0 \pm 0.1$ & 2. $96^{*}$ & (2) $>$ (1) (3) \\
\hline Communication & $2.3 \pm 0.1$ & $2.1 \pm 0.1$ & $2.0 \pm 0.1$ & 4. $48^{*}$ & \\
\hline Role & $2.3 \pm 0.1$ & $2.3 \pm 0.1$ & $2.3 \pm 0.1$ & 0.99 & \\
\hline Emotional response & $2.4 \pm 0.1$ & $2.3 \pm 0.1$ & $2.4 \pm 0.1$ & 0.97 & \\
\hline Emotional intervention & $2.2 \pm 0.1$ & $2.3 \pm 0.1$ & $2.2 \pm 0.1$ & 0.77 & \\
\hline Behavior control & $2.3 \pm 0.1$ & $2.3 \pm 0.1$ & $2.3 \pm 0.1$ & 0.01 & \\
\hline Overall function & $2.3 \pm 0.1$ & $2.2 \pm 0.1$ & $2.0 \pm 0.1$ & $5.59 * *$ & (1) (2) > (3) \\
\hline
\end{tabular}

Note: * $\mathrm{P}<0.05, * * \mathrm{P}<0.01, * * * \mathrm{P}<0.001$

Table 2. Logistic regression analysis of factors related to violent crime

\begin{tabular}{|c|c|c|}
\hline \multicolumn{2}{|c|}{ Independent variable $O \mathrm{R}(95 \% \mathrm{CI})$} & $P$ \\
\hline Emotional abuse & $1.43(1.23 \sim 3.21)$ & 0.007 \\
\hline Psychoticism & $1.06(1.00 \sim 1.13)$ & 0.045 \\
\hline Neuroticism & $1.42(1.00 \sim 1.86)$ & 0.030 \\
\hline Introversion and extroversion & $8.57(1.39 \sim 52.85)$ & 0.021 \\
\hline Overall family function & & 0.001 \\
\hline
\end{tabular}


Table 3. Logistic regression analysis of factors related to property crime

\begin{tabular}{|c|c|c|}
\hline \multicolumn{2}{|c|}{ Independent variable $O R(95 \% C I)$} & $P$ \\
\hline Emotional neglect & $1.48(1.02 \sim 2.10)$ & 0.021 \\
\hline Neuroticism & $1.05(1.00 \sim 1.11)$ & 0.039 \\
\hline Introversion and extroversion & $1.12(1.05 \sim 1.21)$ & 0.001 \\
\hline
\end{tabular}

\section{Discussion}

This study shows that violent criminals often experience emotional abuse and physical neglect in their childhood. They have psychotic, extroverted and neurotic personality traits, low social support, and lack of family communication function and overall function. Property criminals often experience emotional neglect in childhood. They have neurotic and extroverted personality traits, and lack of family problem solving function and overall family function.

A person's crime risk is contained in his experience and encounter, which is a process of accumulation of disadvantages and negative reinforcement [7]. If an adult is antisocial in the future, this pattern will begin at puberty [8]. Some studies show that [9]: 50\% of neglected and abused children are likely to commit juvenile crimes, and $40 \%$ are likely to commit violent crimes. Recent studies have shown that emotional abuse is most likely related to the formation of children's marginal personality [8]. Compared with the control group, children and adolescents suffering from sexual abuse are more likely to be involved in sexual crimes or other criminal crimes [10]. The high aggression, emotional disorder and negative consequences of violent behaviours caused by childhood abuse can directly lead to the occurrence of violent crimes [11]. Chronic neglect of children increases the likelihood of violence. In this study, the violent crime group was subjected to abuse in childhood, especially emotional abuse, sexual abuse and physical neglect. This is consistent with the results of foreign studies [12-13].

Good social support is conducive to physical and mental health, while the existence of bad social relations damages physical and mental health [14]. The research results of Cheng lina show that subjective support and utilization of support in social support are negatively correlated with personality disorder of prisoners [15]. In this study, people in the violent crime group received less objective support than non-criminals and property criminals. The possible reason is that the difference between the subjective experience and the objective existence of the support of the violent criminals leads to the psychological gap and imbalance of the violent criminals, thus contributing to their tendency of violent crimes.

This study shows that violent criminals have psychotic and neurotic personality. The results of this study are consistent with the conclusions of existing studies [16-18]. In this study, compared with non-criminals, violent criminals and property criminals tended to be extroverted, especially the property crime group. The possible reasons are as follows: most of the members of the property crime group are involved in fraud, corruption, illegal production and management, etc. The extroverted person is good at communication, which is more conducive to the above illegal behaviors.

This study shows that the violent crime group has a serious deficiency in family communication and overall family function, and the property crime group has a serious deficiency in family problem solving and overall family function. Juvenile delinquency is closely related to family factors, and the influence of family structure on adolescents is ultimately attributable to the influence of specific family functions on adolescents [19]. Criminologists, sociologists and psychologists put forward many factors leading to crime, including the poor family circumstances, lack of contact with society, making bad companions, the availability of drugs and guns, neurobiological factors, personality factors and family factors, etc. Among them, family factor is regarded as one of the most important influencing factors [20]. Family function variables have been consistently regarded as a strong predictor of juvenile delinquency [21]. Multiple factors of family function are related to the criminal 
psychological structure of juvenile delinquents. If family function is not perfect, it is easy to form the criminal psychological structure and lead to criminal behaviors [22].

\section{Future Research Direction}

This study also has the following shortcomings: (1) it's convenient to get the sample, and not representative, (2) sample size is a little small. Sample can be further expanded in the follow-up studies, considering factors such as school, neighborhood, and life events on influence the formation of crime psychology, to establish a comprehensive, relevant criminal psychological assessment system.

\section{References}

[1]. Mei chuanqiang, Wang min. Criminal psychology [M]. Beijing: China law press, 2005: 273.

[2]. Jin cancan, Zoo Hong, Analysis of influencing factors of juvenile delinquency [J]. Chinese journal of clinical psychology2012,20(6): 78 -79.

[3]. Luo dacha. Criminal psychology [M]. Beijing: China university of political science and law press, 1997: 89-100.

[4]. Jessop R, Donovan Mecosta FM. Beyond adolescence: problem be- heavier and young adult development [M]. New York: Cambridge University Press, 1991.

[5]. Fu wending, Yao shuqiao, Yu Songhua. A study on the reliability and validity of childhood trauma experience questionnaire in college students in China [J]. Chinese journal of mental health, 2005, 13 (1): 40-42.

[6]. Xiao shuiyuan. Theoretical basis and research application of social support assessment scale [J]. Journal of clinical psychiatry, 1994, 4(2): 98- 100.

[7]. [US] Chen xiaojin. \Life course $\backslash$ theory: the persistence and change of individual criminal behaviours $[\mathrm{M}] \| \mathrm{Cao}$ linen, Ren Xin. Criminology: western frontier review in humanities and social science. Beijing: Renin university of China press, 2009: 54.

[8]. Graz KL, Littman R D, Toll MT, et al. Exploring the association between emotional abuse and childhood borderline personality fee- trues: the moderating role of personality traits $[\mathrm{J}]$. Behave There, 2011, 42 (3): 493- 508.

[9]. Bergville AH, Wessel H, Forman A, et al. A deficit in attentional set-shifting of violent offenders [M]. Psyche Med, 2001, 31 (6): 1095- 1105.

[10]. Friedman MS, Marshal MP, Guadamuz TE, et al. A meta-analysis of disparities in childhood sexual abuse, parental physical abuse, and peer victimization among sexual minority and sexual nonmi- nority individuals [J]. Am J Public Health, 2011, 101(8): 1481- 1494.

[11]. Li boohoo, Wang bin Characteristics of impulsive and aggressive personality of male violent criminals and its relationship with childhood abuse [J]. Journal of psychiatry, 2010, 23(2): 119122.

[12]. Van Dorn R, Volavka J, Johnson N. Mental disorder and violence: is there a relationship beyond substance use [J]. Soc Psychiatry Psychiatr Epidemiol, 2012, 47(3): 487- 503.

[13]. Cullen FT. Social support as an organizing concept for criminology- gy: presidential address to the Academy of Criminal Justice Sci- ences [J]. Justice Q, 1994, 11: 528- 559.

[14]. Coyne JC, Downey G. Social factors and psychopathology: stress, social support, and coping processes [J]. Annu Rev Psychol, 1991, 42: 401- 425. 
[15]. Cheng linan. Relationship between parental rearing pattern and social support and personality disorder of prisoners [J]. China public health, 2013, 29(1): 31- 34.

[16]. Sheng yonghui, Yuan jail, Zhao Jing, et al. Differences in personality characteristics between juvenile delinquents and normal juveniles and their family and social factors [J]. China clinical rehabilitation, 2005, 9(20): 84- 85 .

[17]. Goo junked, Yang dean, Yang yang, et al. Research on the correlation between personality of young violent criminals and family environment and parenting style [J]. Journal of Chongqing medical university, 2008, 33 (3): 349- 351.

[18]. Li Jing. The relationship between personality characteristics and family environment of juvenile delinquents in custody [J]. Journal of weaning normal university, 2012, 27(3): 87- 89.

[19]. Dong dank a brief analysis of family factors influencing juvenile delinquency [J]. Modern communication, 2013, (2): 16.

[20]. Zoo Hong, Zhang quilling, Wang Yangchuan. Research progress on the relationship between family function and juvenile delinquency [J]. Psychological development and education, 2005, (3): 120- 123.

[21]. Patterson GR, De Barite BD, Ramsey E. A developmental per- spectate on antisocial behaviour [M]. Amen Psyche, 1989, 44 (2): 329- 335.

[22]. Peng dingo. Investigation on the current situation of family function, self-consciousness and criminal psychological structure of juvenile criminals and its relationship [D]. Changsha: Hunan normal university. 